\title{
Nonverbal Communication of Prison Subculture through Criminal Tattoo Symbols
}

\author{
Barbora VEGRICHTOVÁ ${ }^{6}$
}

\begin{abstract}
The paper discusses the importance of tattoo in the criminal environment and prison subculture. Special attention is paid to the function of tattoos, especially in the area of identification and communication. Frequently used symbols have a considerable explanatory value. They reflect the criminal past of the wearer, expressing religious or ideological beliefs, indicate a process of radicalisation, membership in a criminal group or gang. With the help of analysis of the selected tattoo symbols, it is possible to collect valuable information about the personality profile of a particular individual. The findings presented in the paper are based on the original research project realised in the prison facilities in the Czech Republic.
\end{abstract}

Keywords: communication, convict, criminal, prison, symbol, tattoo

\section{Introduction}

Prison environment is a unique space accumulating different individual with various personal characteristics, behavioural models and sets of opinions, beliefs, attitudes and criminal experiences. Inmates in correctional facilities all over the world represent specific subculture developing and maintaining internal hierarchy, structured system and a so-called convict code of conduct. Convict code or inmate code refers to the unwritten rules and values developed inside prison facilities among convicts as an integral part of a specific social system. Concerning this phenomenon, it needs to be highlighted that informal rules followed by convicts vary with every country, governmental system or legislation background. These norms could only be effective in small populations, where reputations could provide information at a low cost. [1]

Prison subculture fulfil without any doubt the above-mentioned characteristics. Some rules are original and typical only for selected groups of offenders or groups of gangs respecting ethnical, national, cultural or ideological differences. Other rules can be considered traditional norms representing the social standards of the inmate's behaviour, no matter if it relates to correctional facilities in the United States or European Prisons. American sociologist and criminologist Gresham Sykes with a certain generalisation formulated major norms with stable roots almost in all prisons:

- Don't Interfere with Inmate Interests. Never rat on an inmate, don't be nosy, don't have loose lips and never put an inmate on the spot.

- Don't Fight with Other Inmates. Don't lose your head and do your own time.

Ph.D., MBA, assistant professor, Faculty of Law and Public Administration, University of Finance and Administration; e-mail: barbora.vegrichtova@gmail.com 
- Don't Exploit Inmates. If you make a promise, keep it, don't steal from inmates, don't sell favours, and don’t go back on bets.

- Maintain Yourself. Don't: weaken, whine, cop out. Be a man and be tough.

- Don't Trust Guards or the Things They Stand For. Don't be a sucker, the officials are wrong and the prisoners are right. [2]

Among academic sources, this inmate code emphasizes oppositional values to conventional society in general and to prison authorities in particular. The most serious offence against this code of conduct is for an inmate to cooperate with the officials as a snitch. ${ }^{7}$ Incarcerated persons, after their imprisonment, understand very quickly that the most serious contravention of internal norms of prison subculture is cooperation with the prison staff or even denunciation. Loyalty and conformity to the prison subculture is one of the most highly valued rules among the inmates. In simple terms, convicts live by a system of certain tenets inherited with their incarceration, and carried an "us against them" mentality no matter the odds. Loyalty, honour and respect are priceless within the inmate community.

Respect is a value that represents an inmate's sense of masculine standing within the prison subculture. If convicts are disrespected, they are honour-bound to avenge that disrespect or considered weak by other inmates. Any failure to preserve their sense of respect will lead to a question of the inmates' manhood and their ability to handle the time period in a correctional facility. [3]

\section{Nonverbal Communication in Prisons}

Convicts communicate on a daily basis with other inmates, but also with prison staff, educators, pedagogues, attorneys, their family members and relatives. This form of verbal communication is usually under strict control of prison wardens and constantly monitored. Incarcerated persons need to communicate in a secret way, hidden from the permanent monitoring in order to solve their internal matters, transfer important messages, news or warning signs in the daily inmate-to-inmate interaction. Prison slang, used primarily by criminals or incarcerated individuals, is a significant attribute of prison subculture as well, but it is not the paper's purpose to discuss it.

Inmates develop interesting systems of hidden communication which involve different forms and methods of nonverbal expressions. Patterns of demeanour, dress, symbols or gestures are vital in the function of correctional facilities. Convicts use nonverbal communication during their visit when they need to convey something that they do not want the others to hear or understand. They communicate non-verbally when they are ready to start a fight or initiate a prison business. The arrangement of hair, jewellery, clothes, selftouch, short eye contact, changing position of the whole body or crossed arms may symbolise various messages or even instructions for the recipients.

Prison nonverbal code communication were in use from the time prison systems were established and are always developing despite all efforts to combat it. In some cases, the use

A snitch is the label given to an inmate who reveals the activity of another inmate to authorities, usually in exchange for some type of benefit within the prison or legal system. 
of symbols and other methods of nonverbal communication is applied outside correctional facilities as well, especially among street gangs and organised crime syndicates. Infamous and very violent street gangs Crips or Bloods use different hand signs, colour symbols or graffiti on a daily basis. They are used to distinguish the members within the gang but it can also be used to deliver messages to rival gangs. Graffiti signs on the walls serve as a means to intimidate the rivals, to mark the territory or memorialize the death of a gang member. It is a very well-known fact that terrorist and extremist organisations are in connection with different security threat groups and gangs. Ideologically motivated movements use symbols and nonverbal communication as an integral part of their propaganda and violent actions.

The use of secret language of codes and symbols in correctional facilities enable the convicts to traffic in drugs and improvised weapons, to smuggle various contraband items into the prison, to intimidate other inmates, to prepare an escape or riot, to recruit or radicalise the individuals or to plan other criminal and illegal activities.

\section{Methodological Background}

Tattoos are important symbols used by criminals all over the world and in many cases function as a clear and definite indication of gang membership. The explanatory value of tattoo symbols is in real much more complex and represents a helpful tool in the profiling procedure and consequent risk evaluation.

This concept laid the foundation of research project focused on prison environment in the Czech Republic.

In the followings, a brief sum up will be presented of the key methodological background of the project and research environment in the correctional facilities of the Czech Republic.

The population of the Czech Republic is over 10 million and at the beginning of this year the number of prisoners was about 22,000; out of that 1,775 were pre-trial detainees and roughly 1,800 prisoners had a foreign nationality.

In total, there are 35 prisons in the Czech Republic and each prison has its own governor. Approximately 11,000 employees work within the Prison Service of the Czech Republic. The central management is operated by the Prison Service General Directorate under the Ministry of Justice.

There are 4 basic types of prisons in the Czech Republic. They can be classified as follows: minimum, medium, high and maximum security. Those convicts are placed in the minimumsecurity prisons who are sentenced for the least severe offences. Convicts sentenced for the most severe offences are placed in the high and maximum-security prisons. There are more than 11,000 convicts in the high security prisons. In the maximum-security prisons there are roughly 1,000 convicts. There are 48 convicts sentenced to life imprisonment, 45 male and 3 female convicts. ${ }^{8}$

All research subjects (incarcerated persons) were informed of the potential risks and benefits of their participation; they received enough clear information to make a voluntary decision. Conscious consent and voluntary participation are fundamental ingredients of an ethical research. The inmates in the Czech prisons were interviewed by the author and

8 For more information see www.vscr.cz. 
during these procedures the tattoos symbols were documented. Information gathered from respondents was put down in questionnaires prepared in advance. All dates were compared, analysed and the final findings interpreted with regard to content analysis of relevant tattoo symbols, tattoo application methods, tattoo purpose and importance and other causalities.

Data was gathered from a sample of more than one thousand interviewed inmates in 14 correctional facilities, including prisons for female convicts. The findings, which are based on content analysis of tattoo symbols and structured interviews confined in all types of prison facilities, provide substantial support for the theoretical expectations and bring remarkable findings. Concerning expected outputs, the ambition of the research team is the innovation of the information system used by the Czech criminal police and investigation service related to the database of criminal tattoo symbols. The research team have developed an electronic database of criminal tattoo symbols, logically categorizing the relevant symbols in specific groups accompanied with adequate description and risk assessment. Criminal tattoos were evaluated as one of the indicators of potential radicalisation processes and were included in the list of indicators, which are detected and assessed by the Prison Service of the Czech Republic. The Police Academy of the Czech Republic organises and performs a 3-days special course for the employees of the Prison Service entitled Identification of Radicalisation Indicators in Prison Facilities. At the same time, an analytic tool is also developed for detection of radicalised inmates in prisons, with the objective to implement this programme in all correctional institutions in the Czech Republic and other affected security institutions.

\section{Selected Research Findings}

Specific categories of tattoo symbols are characteristic for inmates with notorious criminal background with a tendency to recidivism. For these inmates typical symbols are standing for loss of freedom, stylisation of the role of an incorrigible criminal, adoration of local or foreign personalities of the underworld.

Choosing of a concrete tattoo is of course affected by other inmates and their personal influence. Especially newcomers are affected by the attitudes and social behaviour of prison life. This complicated process of adoption to prison conditions or assimilation into the inmate society is called prisonisation. This term is possibly understood as the process of being socialized into the prison culture. This process occurs over time as the inmate or the correctional officer adapts to the informal rules of prison life.

The process of prisonisation is related and in some cases directly influenced by the individual's radicalisation. Personal trauma accompanied by social isolation, problems in the family and private life, frustration, fear of the uncertain future and existential issues can function as radicalisation drivers. Negative and pessimistic opinions can be manifested and expressed through different tattooed quotations, sayings or sentences.

Typical and very frequent phrases among the convicts in Czech correctional facilities are: Only God can judge me! Live outside the law! Life is a bitch! God forgives, I don't! God gives me a sign! Never give up! Killer! Public enemy number One! etc.

It needs to be highlighted that these sentences are tattooed in various languages, ethnic dialects and criminal slang. 


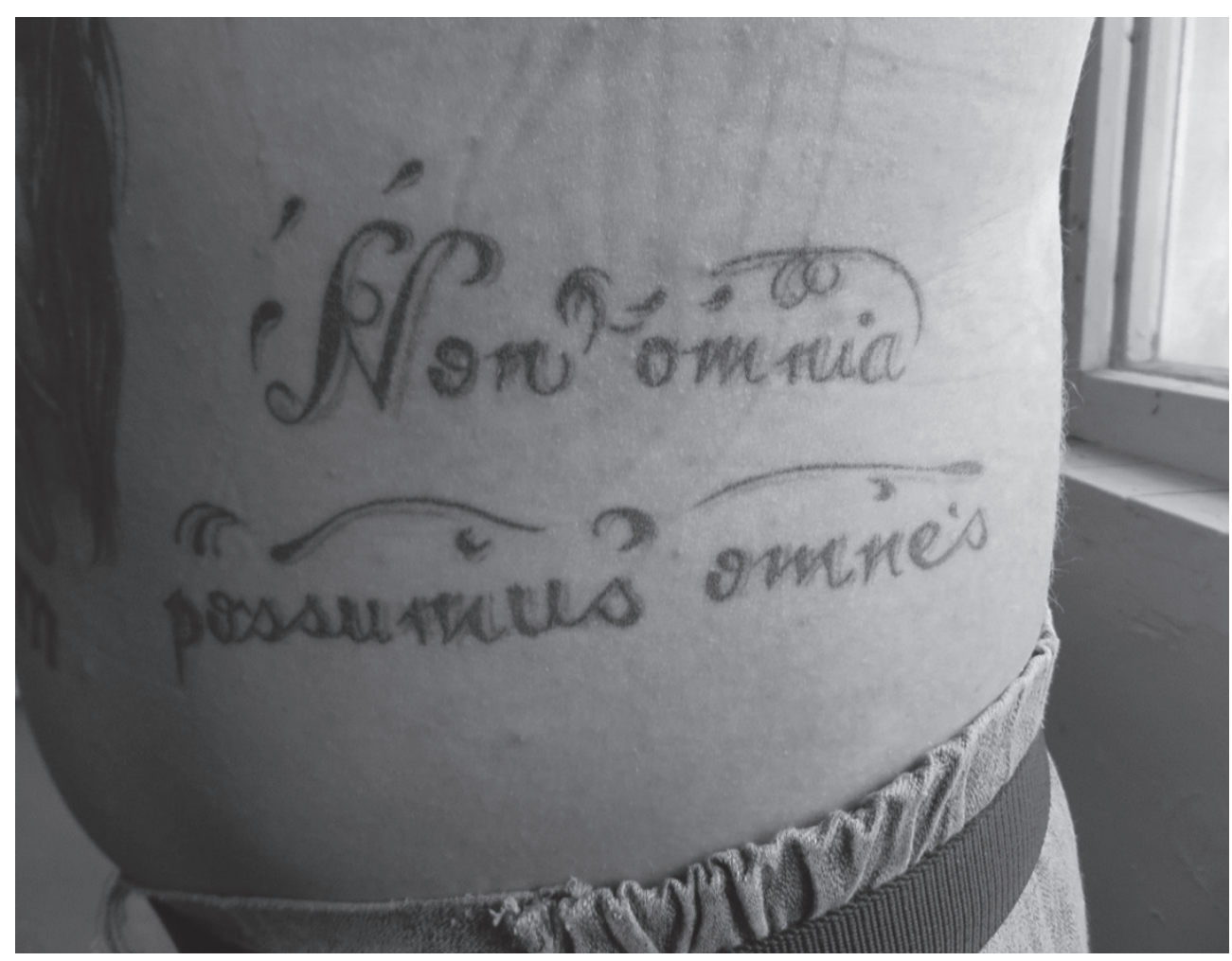

Figure 1. Quotation in Latin language. [Picture made by the author.]

The above presented photo illustrates the popularity of famous quotations among the inmates in Czech correctional facilities. "Non omnia possumus omnes" is a Latin quotation form Virgil, which can be simply translated as: "Not everybody can do everything."

Tattoos simultaneously symbolize a group-organizational association and the hierarchical status of an individual. Prisoners use tattoos to represent their strength and status, to mark their belonging to a certain group, to create a unifying symbol and to define their status and position within their group. [3]

Symbols used by criminals with a rich criminal past in the Czech prison facilities usually prefer symbols with morbid, frustrating and gloomy motifs. Heavily spread are symbols of death, especially sculls with crossbones and figures of Death. The meaning of these motifs have a multiple meaning. Some convicts present their rough nature this way and chosen symbols serve as intimidation tools. Death motifs in different cases refer to the form of crime they committed, most frequently murder or some similar violent act. The symbol of sculls is also very popular among members of Neo-Nazi movements or various outlaw motorcycle clubs. The scull motif with wings is a traditional symbol of the international onepercenter gang, Hells Angels. From the perspective of right-wing extremism, the motif of scull in the traditional design is a well-known symbol of SS units, the infamous paramilitary organisation in Nazi Germany. Right wing extremists using this symbol express this way their loyalty to the Nazi ideology and related attributes. Tattoos are very popular among right wing 
extremists and in some cases could represent a deep fanaticism of the tattoo wearer or even acceleration of a radicalisation process. The phenomenon of radicalisation in prison facilities poses serious security threats not only in correctional facilities but also for the external world.

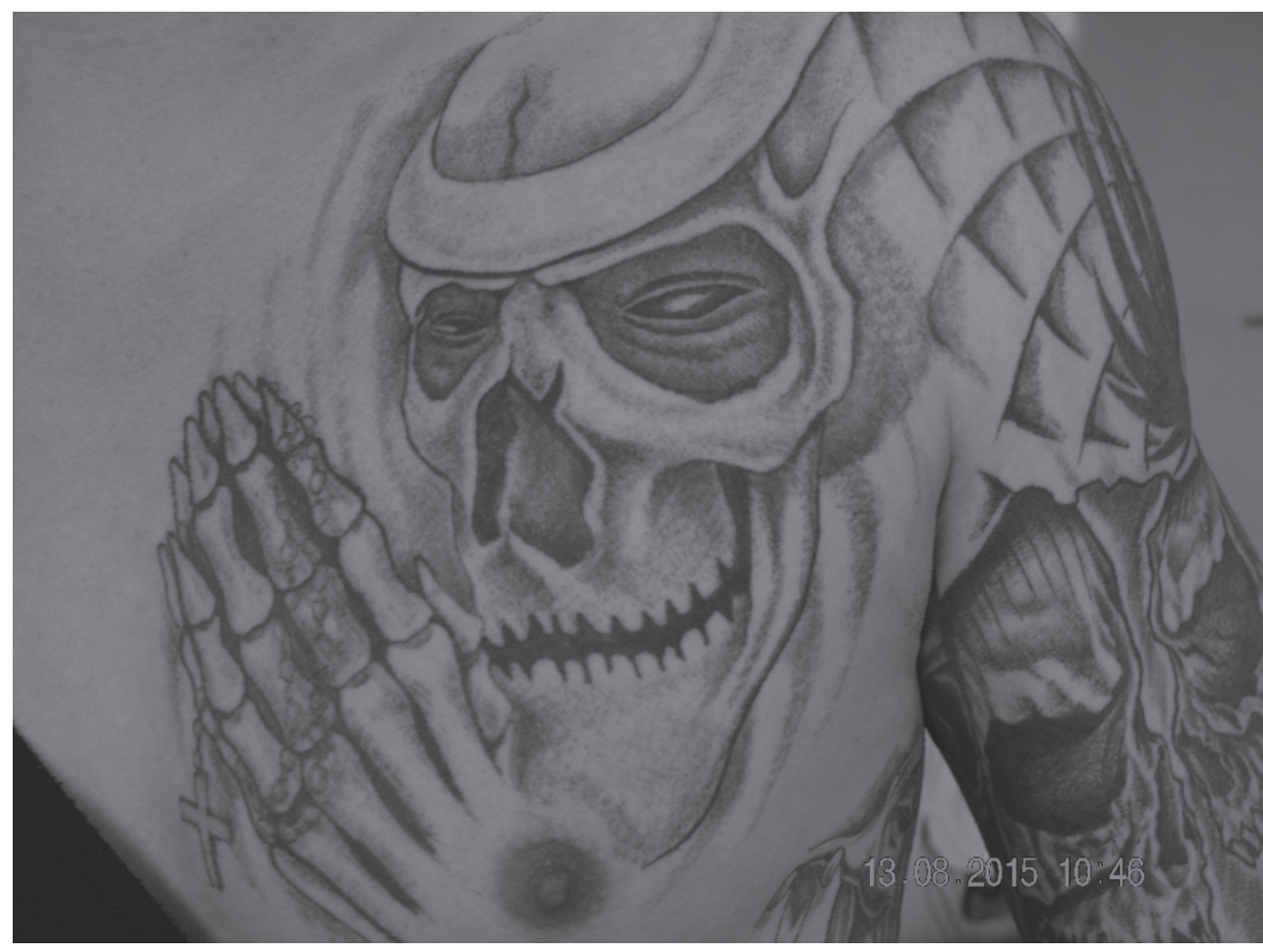

Figure 2. Symbol related to death and morbid topics. [Picture made by the author.]

Radicalisation is usually defined as a process of adopting an extremist belief system, including the willingness to use, support, or facilitate violence, as a method to effect social change. [4] Prisons are often said to have become the breeding grounds for radicalisation. This should come as no surprise. Prisons are "places of vulnerability", which produce "identity seekers", "protection seekers" and "rebels" in greater numbers than other environments. They provide near-perfect conditions in which radical; religiously framed ideologies can flourish. Overcrowding and understaffing circumstances amplify the conditions that lend themselves to radicalisation. Badly run prisons make the detection of radicalisation difficult, and they also create the physical and ideological space in which extremist recruiters can operate at free will and monopolise the discourse about religion and politics.

Certain tattoo symbols documented in correctional facilities may show the individual's transformation or a change in his/her ideological or religious belief.

Extremism and terrorism are among the security threats for the Czech Republic, on the other hand, in comparison with West European countries this threat is less immediate. The level of extremism in the Czech society is rather low, revealed cases of radicalized individuals willing to commit politically or religiously motivated criminal acts e.g. foreign 
fighters, are rather exceptional. But in conformity with the current situation in Europe, Czech inmates are getting radicalised or are imprisoned already being radicalised and contrary to the social situation it is not exceptional. [6]

Politically oriented extremists represent an integral part of the Czech prison subculture. Sentenced and imprisoned followers of extremist ideologies are usually intensively supported by the extremist scene. From this perspective, they are introduced and presented as martyrs, heroes or even so-called prisoners of war (P.O.W). Following this concept, Czech extremists are engaged in fund-raising, organise and attend public assemblies and write different comments on the internet and social media in order to help and support their fellows. Such efforts can be detected in the correspondence of classical written communication, as well.

Tattoo symbols can represent the extremist's resistance against the penitentiary system; it is a way of hostile attitude toward prison staff. The most frequently used tattoo symbol in the Czech prison facilities is an anti-police acronym ACAB (All Cops Are Bastards), manifested in countless designs and coded variations.

These symbols and other threatening and hateful symbols can be assessed as serious warning signs of an ongoing radicalisation process or as an indicator of a violent individual.

\section{Conclusion}

Higher awareness or even professional knowledge about nonverbal communications and symbols related to different ideologies, movements, extremist organisations and gangs could contribute to the effective prevention in this field. The basis of successful tattoo analysis is educated prison staff and mutual sharing of information among the security bodies and academic sphere. The constructive approach to this issue and reciprocal cooperation as a basis makes prevention and intervention as effective and successful as possible.

Criminal tattoos as a way of nonverbal communication in correctional facilities play a multiple role in the process of appropriate detection of dangerous persons and individuals involved in gangs, radicalised inmates or even members of extremist or terrorist groups. The early warning system based on professional and correct detection, together with adequate security measures, constitute the fundamental pillars of crime and terrorism mitigation.

\section{References}

[1] SKARBEK, D.: The Social Order of Underworld. New York: Oxford University Press, 2014.DOI: https://doi.org/10.1093/acprof:oso/9780199328499.001.0001

[2] CLEAR, T. R., RESIG, M. D., COLE, G. F.: American Corrections. Seventh Edition. Boston: Cengage Learning, 2006.

[3] HANSER, D. R.: Introduction to Corrections. Prison Subculture and Prison Gang Influence. Chapter 10. www.sagepub.com/sites/default/files/upm-binaries/50421_ch_10.pdf (Downloaded: 11.07.2018)

[4] SHOHAM, E.: Prison Tattoos. A study of Russian Inmates in Israel. New York: Springer International Publishing, 2015. 
B. VEGRICHTOVÁ: Nonverbal Communication of Prison Subculture through Criminal Tattoo Symbols

[5] HR 1955 (110 th $)$ : Violent Radicalisation and Homegrown Terrorism Prevention Act of 2007. Homeland Security Institute, Radicalisation: An Overview and Annotated Bibliography of Open-Source Literature. Final Report (Arlington: HSI, 2006), 2-12. “The term 'violent radicalisation' has been defined as the process of adopting or promoting an extremist belief system for the purpose of facilitating ideologically based violence to advance political, religious, or social change.” www.govtrack.us/congress/bills/110/hr1955/text (Downloaded: 24.10.2007)

[6] VEJVODOVÁ, P., KOLÁŘ, O.: Radicalisation in Czech prisons: empowering of prison staff as "must" for effective facing the issue. In. $17^{\text {th }}$ Annual Conference of the European Society of Criminology. Cardiff, September 13-16, 2017. 